\title{
RESPONSABILIDADE PROFISSIONAL E DOCUMENTAÇÃO ODONTOLÓGICA - REVISÃO DE LITERATURA
}

\author{
Salen Marchesi de Almeida', Fábio Delwing ${ }^{2}$, Maria da Penha Siqueira Assis ${ }^{3}$, \\ Frederico Mamede Santos Furtado ${ }^{4}$, Juliana Aires Paiva de Azevedo'
}

Autora para correspondência: Salen Marchesi de Almeida - salenmarchesi@hotmail.com 'Perita Odontolegista da Polícia Civil do Maranhão no Instituto Médico Legal de São Luís. São Luís, Maranhão, Brasil. ${ }^{2}$ Perito Odontolegista da Polícia Civil do Maranhão no Instituto Médico Legal de São Luís. São Luís, Maranhão, Brasil. ${ }^{3}$ Mestre. Professora na Professora na Universidade Vale do Rio Doce. Governador Valadares, Maranhão, Brasil. ${ }^{4}$ Encarregado do Serviço de Tanatologia do Instituto Médico Legal de São Luis. São Luís, Maranhão, Brasil.

RESUMO | Introdução: No exercício da Odontologia, o cirurgião-dentista está sujeito a ser responsabilizado por suas ações ou omissões que resultem em danos aos seus pacientes. Essa responsabilização pode ocorrer na esfera ética, civil e penal, entre outras. Ao longo dos anos, a sociedade e a relação profissional-paciente têm se modificado apoiadas nas legislações vigentes, assim como na disseminação da informação e da comunicação. Desse modo, tem se visto um crescente número de litígios envolvendo cirurgiões-dentistas e pacientes, o que revela a importância dos profissionais conhecerem as normas que regulamentam o exercício da Odontologia, bem como, as consequências do ato ilícito. Objetivos: O presente trabalho teve como objetivos fornecer conhecimento, por meio de uma revisão de literatura, sobre $\bigcirc$ aspecto legal da responsabilidade profissional do cirurgião-dentista e destacar a importância da documentação odontológica como meio de prova da atuação profissional. Métodos: Foram utilizados livros, teses e artigos científicos publicados em bases eletrônicas como SciELO, Bireme, MedLine e Lilacs, no idioma Português, além de leis e normativas publicadas em endereços eletônicos oficias. Conclusões: Concluiu-se que um prontuário adequado resguarda o profissional; assim como uma documentação falha, compromete todo o trabalho realizado e pode resultar em uma condenação.

Palavras-chave: Documentação; odontologia legal; responsabilidade profissional. 


\section{INTRODUÇÃO}

A vida em sociedade é regulamentada por normas que buscam harmonizar o convívio social, garantindo direitos e deveres aos cidadãos em todas as esferas, inclusive no exercício profissional. As leis e os códigos de ética profissionais são diretrizes que norteiam o desempenho das atividades laborais e exigem do profissional conhecimentos, habilidades e responsabilidades no desempenho de suas funções.

No Brasil, o exercício da Odontologia é regulamentado pela lei $n^{\circ} 5.081$ de 1966'. Dentre os dispositivos legais que envolvem a profissão estão, ainda, a Constituição Federal (CF), o Código de Ética Odontológica (CEO), Código Civil (CC), Código de Defesa do Consumidor (CDC) e o Código Penal $(\mathrm{CP})^{2}$.

Segundo o CEO (2012) ${ }^{3}$, a Odontologia é uma profissão que se exerce em benefício da saúde do ser humano, da coletividade e do meio ambiente, sem qualquer discriminação. Assim, o cirurgiãodentista tem o compromisso de contribuir para a saúde bucal das pessoas ${ }^{4}$, estando sujeito a ser responsabilizado por seus atos ou suas omissões ${ }^{5}$. Dentre as esferas nas quais podem ocorrer essa responsabilização estão a ética, civil e penal ${ }^{2}$.

Ao longo dos anos, a sociedade e a relação profissional-paciente tem se modificado. Com - advento do CDC, introduzido na legislação brasileira em 1990, a sociedade está mais consciente dos seus direitos e amparada na sua busca ${ }^{6}$. O referido código, visando proteger 0 consumidor, polo hipossuficiente nas relações de consumo, assegurou maior equilíbrio nas relações jurídicas travadas entre fornecedores de produtos e serviços e consumidores ${ }^{7,8}$. Com tal característica, os pacientes têm reivindicado judicialmente, de forma mais incisiva os seus direitos ${ }^{8}$.

Outro fator fundamental na modificação desse comportamento é a atuação da mídia, que contribui com a disseminação do conhecimento sobre os direitos do consumidor e dedica grande espaço aos casos chamados "erros médicos" . Outrossim, a atual realidade do mercado de trabalho, altamente competitivo, faz com que alguns profissionais adotem condutas de risco, como horas exaustivas de trabalho e condições operatórias inadequadas, que podem resultar em falhas ${ }^{10}$.

Em decorrência disso, tem-se observado o crescimento acentuado de litígios envolvendo cirurgião-dentista e paciente, seja por acusação de erro profissional, iatrogenia, cobrança de honorários, ou qualquer outro motivo que leve à desarmonia entre as partes ${ }^{1}$.

Diante esse novo cenário, faz-se necessário uma nova postura profissional: a "Odontologia defensável", que não se trata de uma nova especialidade odontológica, mas sim de uma nova maneira de conduzir as práticas de trabalho, com a adoção de medidas preventivas capazes de resguardar - profissional em eventuais processos ${ }^{12}$. Neste contexto, 0 presente trabalho teve como objetivo fornecer conhecimento sobre o aspecto legal da responsabilidade profissional do cirurgião-dentista, destacando a documentação odontológica como instrumento de prova da conduta profissional.

\section{MÉTODO}

Foi realizada uma revisão de literatura por meio de livros, teses e artigos científicos publicados em bases eletrônicas como SciELO, Bireme, MedLine e Lilacs, além de leis e normativas publicadas em endereços eletônicos oficias. Foram utilizados os seguintes unitermos: "documentação", "odontologia legal", "responsabilidade profissional", "odontologia", "má conduta profissional", "imperícia". O período da busca de artigos foi entre os meses Agosto e Dezembro do ano de 2016.

Os critérios de inclusão para a seleção dos artigos foram: artigos disponíveis na íntegra e publicados em Português, que mantivessem relação com o tema da revisão. Os critérios de exclusão foram: repetição de material bibliográfico e fuga do tema analisado. 


\section{REVISÃO DE LITERATURA}

Legislação

No campo da responsabilidade ética, o cirurgiãodentista é regido pelo Código de Ética Odontológica que regula os direitos e deveres da profissão. $O$ código expõe o conjunto de condutas, princípios morais e valores que devem ser observados no exercício profissional e define as sanções sujeitas àqueles que $\circ$ infringirem, ainda que de forma indireta ou omissa ${ }^{3}$.

Dentre os deveres fundamentais do cirurgiãodentista instituídos pelo CEO, está o de exercer a profissão mantendo comportamento digno, elaborar e manter atualizados os prontuários, incluindo os prontuários digitais, além de permitir o seu acesso ao paciente ou a seu responsável legal. Determina, ainda, que a elaboração, bem como a manutenção do prontuário, deva ser legível e sua conservação em arquivo próprio, seja de forma física ou digital ${ }^{3}$. O descumprimento das normas contidas no CEO é caracterizado como infração ética e para apuração dos fatos será aplicado o que dispõe o Código de Processo Ético Odontológico $(\mathrm{CPEO})^{13}$.

De um modo geral, a responsabilidade civil é imputada ao profissional quando uma norma contida na $C F$, no CC ou no CDC for infringida ${ }^{14}$, devendo, para tanto, ficar provado no processo a existência de conduta culposa do profissional, dano ao paciente e nexo de causalidade entre $\circ$ ato do profissional e o dano causado ${ }^{15}$. A responsabilidade civil pode ser definida como o dever jurídico de reparação do dano sofrido, imposto ao seu causador direto ou indireto, pela prática de um ato ilícito ou pela inobservância de normas ${ }^{5,16}$.

A existência de dano, seja ele material ou moral, é - principal elemento da responsabilidade civil $^{5}$, que tem como fundamento o restabelecimento através de indenização pecuniária, do equilíbrio jurídico alterado pela ocorrência da lesão ${ }^{17}$.

Código Civil (2002) $)^{18}$ determina, no artigo 186 que aquele que, por ação ou omissão voluntária, negligência ou imprudência, violar direito e causar dano a outrem, ainda que exclusivamente moral, comete ato ilícito. No artigo 927 o código supracitado traz a obrigação de reparar $\circ$ dano causado a outrem, e, determinar no artigo 951 a aplicação de indenização devida para aquele que, no exercício de atividade profissional, por culpa, causar a morte do paciente, agravar-lhe o mal, causar-lhe lesão ou inabilitá-lo para o trabalho.

O Código de Defesa do Consumidor $(1990)^{19}$ é - responsável pelo estabelecimento de normas de proteção e defesa do consumidor. Tal código equiparou os profissionais da Odontologia a prestadores de serviço e garantiu aos pacientes/ consumidores 0 direito de reclamar pelas falhas, defeitos ou danos decorridos do tratamento odontológico prestado. No seu artigo 3 conceitua fornecedor como toda pessoa física ou jurídica, pública ou privada, nacional ou estrangeira, que desenvolvem atividades de produção, criação, construção, transformação e prestação de serviços, entre outras. Acrescenta no artigo 14 o dever do fornecedor de reparação dos danos causados aos consumidores.

Além disso, o referido código estabelece, no artigo 6, inciso VIII, como direito básico do consumidor, a facilitação da defesa de seus direitos, inclusive com a inversão do ônus da prova, a seu favor, no processo civil, quando, a critério do juiz, for verossímil a alegação ou quando for ele hipossuficiente, segundo as regras ordinárias de experiências ${ }^{19}$.

$\mathrm{Na}$ esfera penal, o cirurgião-dentista pode ser indiciado por alguma conduta tipificada como crime no Código Penal ${ }^{10,14,20}$. Dentre os crimes relacionados aos profissionais da Odontologia estão, entre outros: o exercício ilegal da profissão (artigo 282), a violação do sigilo profissional (artigo 154), falsidade ideológica (artigo 299), estelionato (artigo 171), lesões corporais (artigo 129) ${ }^{10}$ e o homicídio (artigo 121 ) 21, 22 .

O crime de exercício ilícito da Odontologia é caracterizado pela atuação profissional sem autorização legal, ou excedendo os limites impostos para a profissão ${ }^{10,20}$. A violação de segredo profissional ocorre quando $\circ$ cirurgião-dentista revela, sem justa causa, fato relacionado ao paciente de que tenha conhecimento em razão de sua função, ministério, ofício ou profissão, e cuja revelação pode produzir dano a outrem ${ }^{10,14,20}$. 
Entretanto, a confidencialidade desse segredo não é absoluta ${ }^{10}$. A quebra do sigilo pode ocorrer mediante o consentimento do paciente ou de seu representante legal ou sob o amparo da legislação, em determinadas situações chamadas de justa causa $^{23}$. As hipóteses de justa causa estão elencadas no CEO, sendo elas: notificação compulsória de doenças, colaboração com a justiça nos casos previstos em lei, perícia odontológica nos seus exatos limites, estrita defesa de interesse legítimo dos profissionais inscritos, revelação de fato sigiloso ao responsável pelo incapaz ${ }^{3}$.

A falsidade ideológica aplica-se quando o profissional emite um documento falso, como por exemplo, um atestado com informações ilegítimas, as quais não pode comprovar ${ }^{10,14,22}$. Destaca-se que é dever do profissional atestar apenas fatos verdadeiros, vivenciados em sua prática clinica ${ }^{10}$.

Já o crime de estelionato ocorre com a obtenção de vantagem ilícita, em prejuízo alheio, induzindo ou mantendo alguém em erro ${ }^{20}$. Na odontologia verifica-se vantagem ilícita, quando o profissional negocia com o paciente um determinado tratamento e executa outro de qualidade inferior ${ }^{22}$.

A lei penal versa também sobre as lesões corporais, incluindo a modalidade culposa ${ }^{20}$, podendo - cirurgião-dentista ser acionado na seguinte situação: da prática odontológica resultar lesão ao paciente ${ }^{10,14,21,22}$. É importante lembrar que a atividade odontológica é invasiva e faz uso de instrumental cortante, contundente e cortocontundente que podem ocasionar lesões ${ }^{22}$.

Contudo, os danos produzidos, frequentemente, são inerentes ao tratamento realizado e devem ser esclarecidos aos paciente, considerando o risco de responder por omissão ${ }^{10}$. Tal lei traz ainda, porém fortuita, a possibilidade de enquadramento no crime de homicídio na modalidade culposa ${ }^{22}$.

\section{Prontuário odontológico}

O prontuário odontológico é a ferramenta que o cirurgião-dentista dispõe para registrar todas as informações relacionadas ao paciente e pertinentes ao tratamento. Nele está registrado o diagnóstico, prognóstico e eventuais intercorrências, permitindo a continuidade do tratamento e o acompanhamento da evolução do paciente. Fichas clínicas, radiografias e modelos são exemplos de peças que o compõe $e^{9,24}$.

Tem função de comprovar, a qualquer tempo, que - profissional zelou pelos cuidados de saúde do paciente dentro dos princípios preconizados pela ciência odontológica, além de representar o mais importante veículo de comunicação entre os membros da equipe de saúde responsável pelo atendimento ao paciente ${ }^{25}$.

Sua finalidade primária é clinica, podendo ter aplicação pericial, como no caso das identificações humanas post-mortem ${ }^{22,24}$, bem como, ensejar efeitos jurídicos ${ }^{8,9}$.

Para que possa, todavia, produzir os resultados legais desejados é fundamental que seja elaborado cumprindo requisitos administrativos, éticos e legais, pois uma falha nesse processo pode comprometer sua validade ${ }^{26}$.

Sabendo de sua importância, o Conselho Federal de Odontologia (CFO) disponibiliza em seu site um modelo que pode ser adaptado à realidade de cada profissional. Dentre as orientações apresentadas no modelo, está a necessidade de que a ficha clínica contenha os dados do profissional e do paciente, ou de seu responsável legal ou cônjuge, em caso de menores de 18 anos ou incapazes?. Ela representa um documento clínico, cirúrgico, odontolegal e de saúde pública ${ }^{27}$. A anamnese deve ser feita de forma clara, devendo ser assinada pelo paciente, a fim de atestar a veracidade das informações prestadas. Anotações detalhadas quanto às condições bucais pré-existentes deverão ser registradas em odontograma para melhor visualização. $O$ plano de tratamento deve especificar os procedimentos a serem realizados, a técnica e o material envolvido. É importante deixar explícito no documento todas as opções de tratamento possíveis e indicadas, para que o paciente exerça sua autonomia na escolha da opção que melhor se adapta, devendo ainda, assinar um termo de consentimento livre e esclarecido (TCLE) 9 .

A evolução do tratamento, as intercorrências e os procedimentos concluídos também devem ser registrados minuciosamente. Exames complementares 
como radiografias, modelos e fotografias devem ser processados, rotulados, identificados e arquivados corretamente 9 . Documentos fornecidos ao paciente, como receitas e atestados, devem ter suas cópias, devidamente assinadas pelo paciente, anexadas ao seu prontuário ${ }^{22}$. Um prontuário adequado deve conter todas as informações relevantes ao tratamento $2,9,22,24$.

Além da correta elaboração, há também a necessidade de armazenamento apropriado e guarda do prontuário por tempo indeterminado, para que as informações sejam preservadas ${ }^{8,9}$.

\section{DISCUSSION}

A responsabilidade profissional do cirurgiãodentista envolve as esferas ética, civil e penal. Um mesmo ato pode motivar processos em apenas uma dessas esferas, em duas delas, ou até mesmo nas três ${ }^{15}$.

A instância civil é constantemente acionada para resolução desses litígios, visto que nesta esfera jurídica $\circ$ paciente deseja receber vantagem pessoal direta (indenização) pelo dano material ou moral que julga ter sofrido em decorrência do tratamento odontológico recebido ${ }^{5,7,15}$. Entretanto não é incomum que pacientes insatisfeitos recorram ao conselho de ética e à justiça criminal, mesmo não obtendo vantagem direta em caso de condenação do profissional ${ }^{15}$.

Vale destacar que, a princípio as instâncias são independentes e a decisão em uma delas não necessariamente implica na mesma decisão em outra. Contudo, há exceções, nas quais haverá vinculação entre as instâncias como, por exemplo, a decisão condenatória no processo criminal faz coisa julgada no processo civil ${ }^{15}$.

Dentre as normas estabelecidas pelo CDC, destacase o mecanismo da inversão do ônus da prova. Tratase de um dispositivo legal que possibilita que a defesa dos direitos dos consumidores seja facilitada. Em regra, o ônus de provar em processos civis cabe a quem alega $\circ$ fato $^{26}$. Na prática, em um processo no qual o paciente acusa o cirurgião-dentista de terIhe causado um dano, seria dele a função de provar a culpa do profissional. Com a inversão do ônus da prova, passa a ser do profissional a obrigação de demonstrar sua idoneidade e que trabalhou dentro dos princípios éticos e legais preconizados ${ }^{28}$.

De fato, por possuir o dever de elaborar e manter atualizado o prontuário do paciente é o cirurgião-dentista que dispõe dos meios de provar - que realmente aconteceu durante $o$ tratamento odontológico. Neste sentido, o prontuário odontológico torna-se o principal instrumento de defesa da conduta profissional, demonstrando sua boa-fé.

Quando bem elaborados, detalhados e atualizados, os prontuários evidenciam um profissional comprometido, consciente e zeloso, assim como a colaboração ou não do paciente com relação ao tratamento. Em contrapartida, prontuários mal estruturados, omissos, desatualizados, com informações obscuras, mal preservados, não resguardam o profissional, ao contrário, podem servir de prova negativa, revelando sua negligência e descuido com o paciente.

\section{CONCLUSÕES}

A compreensão, pelo cirurgião-dentista, do cenário atual da Odontologia, da mudança na relação paciente-profissional e das leis que norteiam a profissão e a sociedade em geral, é indispensável para $\circ$ bom desempenho laboral. O estudo da legislação pertinente mostrou que o cirurgião-dentista deve respeitar princípios morais e valores, cumprir com seus deveres profissionais e comprometer-se com a adequada assistência aos seus pacientes; mostrou ainda, que $\circ$ profissional é responsável por seus atos e omissões, podendo ser acionado, na ocorrência de litígios, nas esferas ética, civil e penal. Sendo assim, ganha destaque a "Odontologia defensável", que nada mais é que a adoção de práticas seguras de trabalho, como a produção adequada da documentação odontológica, uma vez que, na solução de conflitos, é comum que $\circ$ profissional tenha que comprovar 
sua conduta. Um prontuário adequado resguarda o profissional, assim como uma documentação falha, compromete todo o trabalho realizado e pode resultar na sua condenação.

\section{CONTRIBUIÇÕES DOS AUTORES}

Almeida SM participou da concepção, delineamento, busca e análise dos dados da pesquisa, interpretação dos resultados, redação e encaminhamento do artigo científico. Delwing $F$ e Assis MPS participaram da coleta de dados da pesquisa, interpretação dos resultados e redação do artigo científico. Furtado FMS e Azevedo JAP participaram da concepção, busca dos dados da pesquisa, redação e encaminhamento do artigo científico.

\section{CONFLITOS DE INTERESSES}

Nenhum conflito financeiro, legal ou político envolvendo terceiros (governo, empresas e fundações privadas, etc.) foi declarado para nenhum aspecto do trabalho submetido (incluindo mas não limitandose a subvenções e financiamentos, conselho consultivo, desenho de estudo, preparação de manuscrito, análise estatística, etc).

\section{REFERÊNCIAS}

1. Brasil. Presidência da República. Lei $n^{\circ} 5.081$, de 24 de agosto de 1966. Regula o exercício da Odontologia. Brasília, DF. 1966.

2. Medeiros UV. Odontologia Legal e Legislação Odontológica [Internet]. 2011 [acesso 8 ago 2016]. Available at: https://saudebucalcoletivaveri.files.wordpress. com/201 1/02/odontologia-legal-e- legislac3a7c3a3oodontolc3b3gica2.pdf.

3. CFO - Conselho Federal de Odontologia. Revoga o Código de Ética Odontológica aprovado pela Resolução CFO-42/2003 e aprova outro em substituição. Resolução $n^{\circ}$ 118 , de 11 de maio de 2012.

4. Medeiros UV, Coltri AR. Responsabilidade civil do cirurgião-dentista. Rev. Bras. Odontol. 2014;71(1):10-6.

5. Thebaldi IMM, Pena ISO. A necessidade do consentimento informado na prática da odontologia e sua relação com a responsabilidade civil do cirurgião-dentista. Revista do CROMG. 2014;15(2):6-14.

6. Holanda DAd, Melo VVCd, Zimmermann RD. Digital odontological documentation. Odontol. clin.-cient. 2010;9(2):111-13.
7. Figueira Junior E, Trindade GO. Responsabilidade do Cirurgião Dentista Frente ao Código de Defesa do Consumidor. Cadernos UniFOA. 2010;1 2:63-70.

8. Fonseca GS, Azevedo ACS, Diniz DSOL, Menezes FS, Silva MLCA, Musse JO, Marques JAM. Aspectos legais da utilização do prontuário digital na odontologia. RBOL. 2014;1(1):6977. doi: $10.21117 /$ RBOL.V111.9

9. Brasil. Conselho Federal de Odontologia. Prontuário odontológico: uma orientação para o cumprimento da exigência contida no inciso VIII do art. $5^{\circ}$ do Código de Ética Odontológica. Rio de Janeiro. RJ. 2004.

10. Lolli LF, Lolli MCGS, Marson FC, Silva CO, Moreira MA, Silva HA. Responsabilidade criminal do cirurgião dentista. Acta Jus. 2013;1(1):17-23.

11. Ramos DIA. Prontuário odontológico: aspectos éticos e legais [dissertação]. São Paulo (SP): Faculdade de Odontologia de Piracicaba da Universidade Estadual de Campinas; 2005.

12. Cerveira JGV. A legalidade dos documentos digitais. Odontol. clín.-cient. 2008;7(4):299-302.

13. Brasil. Conselho Federal de Odontologia. Resolução CFO59/2004: Código de Processo Ético Odontológico. Brasília, DF. 2004.

14. Nogueira TH, Santos CC, Petroski TCA, Galvão APB, Neto Filho MA, Lolli MCGS, Lolli LF. A responsabilidade profissional do cirurgião dentista docente. BJSCR. 2014;8(3):84-91.

15. Coltri $M$. As esferas de responsabilidade do Cirurgiãodentista no atendimento ao paciente. [Internet]. 2012. [acesso 15 ago 2016 ]. Available at: http://www.odontosites.com.

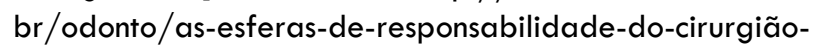
dentista-no-atendimento-ao-paciente.html

16. Albuquerque Junior HP. Responsabilidade civil de cirurgiões dentistas em razão de procedimentos estéticos. [Internet]. 2011 . [accessed 15 ago 2016]. Available at: http://egov.ufsc.br/portal/sites/default/files/ anexos/32547-39641- 1-PB.pdf

17. Cavalieri Filho S. Programa de Responsabilidade Civil. 9.ed. São Paulo: Atlas; 2010.

18. Brasil. Lei $n^{\circ} 10.406$ de 10 de janeiro de 2002. Institutes the Civil Code. Brasilia, DF. 2002.

19. Brasil. Lei ${ }^{\circ} 8.078$, de 11 de setembro de 1990. Dispõe sobre a proteção do consumidor e da outras providencias. Brasília. DF. 1990.

20. Brasil. Lei ${ }^{\circ} 2.848$ de 07 de dezembro de 1940 . Código Penal. Rio de Janeiro. RJ. 1940. Portuguese.

21. Costa KS. A responsabilidade penal do cirurgião 
dentista. [Internet]. Santa Catariana, 2007. [accessed 20 ago 2016]. Available at: http://www.egov.ufsc.br/portal/sites/ default/files/anexos/13158-13159-1-PB.pdf

22. Vanrell JP. Odontologia Legal e Antropologia Forense. 2.ed. Rio de Janeiro: Guanabara Koogan; 2009.

23. Dias OV, Gomes LMX, Barbosa TLA, Souza LPS, Rocha ALF, Costa SM. Segredo profissional e sua importância na prática de enfermeiros e odontólogos. Rev. Bioet. 2013;21(3):448-54. doi: 10.1590/S1983$\underline{80422013000300009}$

24. Benedicto EN, Lages LHR, Oliveira OF, Silva RHA, Paranhos LR. A importância da correta elaboração do prontuário odontológico. Odonto. 2010; 18(36):41 -50. doi: 10.15603/2176-1000/odonto.v18n36p41-50

25. Saales Peres A, Silva RHA, Lopes Junior C, Carvalho SPM. Prontuário odontológico e o direito de propriedade científica. Rer. Gaucha Odontol. 2007; 55(1):83-88.

26. Silva M. Compendio de odontologia legal. 1 ed. Rio de Janeiro: Medsi; 1997.

27. Massad E, Marin HF, Azevedo Neto RS. O prontuário eletrônico do paciente na assistência, informação e conhecimento médico. São Paulo: Universidade Federal de São Paulo; 2003. p. 1-20.

28. Bohrer C. A inversão do ônus da prova nas soluções de conflito nas relações de consumo. [Internet]. Academia Brasileira de Direito Processual Civil. [acesso 21 ago 2016]. Disponível em: http://www.abdpc.org.br/abdpc/artigos/ CRISTINA\%2OBOHRER\%20-\%20ve rs\% C3 \%A30\%20final. pdf 